\title{
Protective Effect of ACTIValoe N-931 Complex, a Mixture of Aloe vera and Silybum marianum, on Experimental Acute Liver Injury
}

\author{
Young-Joo Moon ${ }^{1}$, Ho-Jun Cheon ${ }^{1}$, Woo-Cheol LeE ${ }^{1}$, Hyo-Yeon Kim${ }^{1}$, Sun-Tack OH${ }^{2}$, \\ Eun-Ju SHIN ${ }^{2}$, Kyu-Suk SHIm² and Sun-Mee LeE ${ }^{1,{ }^{*}}$ \\ ${ }^{1}$ College of Pharmacy, Sungkyunkwan University, Suwon, Gyeonggi-do, Korea \\ ${ }^{2}$ Univera, Inc., ECONET CENTER 302-4, Sungsu-dong 2 Ga, Sungdong-gu, Seoul 133-120, Korea
}

(Received June 17, 2008; Revised June 30, 2008; Accepted July 7, 2008)

\begin{abstract}
The aim of this study was to investigate the hepatoprotective effect of ACTIValoe ${ }^{\circledR} \mathrm{N}-931$ complex, a mixture of Aloe vera and Silybum marianum, against acute liver injuries. Acute liver damages were induced by intraperitoneal injection of galactosamine (GalN, $700 \mathrm{mg} / \mathrm{kg}$ ), naphthylisothiocyanate (ANIT, $40 \mathrm{mg} / \mathrm{kg}$ ) and ethionine $(500 \mathrm{mg} / \mathrm{kg})$. ACTIValoe ${ }^{\circledR} \mathrm{N}-931$ complex $(85,170$ and 340$)$ was administered orally $48 \mathrm{~h}, 24 \mathrm{~h}, 2 \mathrm{~h}$ before and $6 \mathrm{~h}$ after the injection of hepatotoxins. At $24 \mathrm{~h}$ after GalN treatment the levels of serum aminotransferases and hepatic lipid peroxidation were significantly elevated, whereas hepatic glutathione, serum triglyceride (TG) and total cholesterol were decreased. These changes were attenuated by ACTIValoe ${ }^{\circledR}$ $\mathrm{N}-931$ complex. The serum aminotransferase activities and total bilirubin significantly increased at $48 \mathrm{~h}$ after ANIT treatment, but were attenuated by ACTIValoe ${ }^{\circledR} \mathrm{N}-931$ complex. The bile flow was lower after ANIT treatment, which was restored by ACTIValoe ${ }^{\circledR} \mathrm{N}-931$ complex. ACTIValoe ${ }^{\circledR} \mathrm{N}-931$ complex reduced the ethionine-induced elevated hepatic TG contents. Histopathological analysis revealed that signs of liver injury were prominent at $24 \mathrm{~h}$ as result of ethionine injection, demonstrated by extensive areas of fatty change and microvesicular steatosis were observed around cells. These changes were attenuated by ACTIValoe ${ }^{\circledR} \mathrm{N}-931$ complex. Our results suggest that the ACTIValoe ${ }^{\circledR} \mathrm{N}-931$ complex has a protective effect on acute liver injury.
\end{abstract}

Keywords: ANIT, Ethionine, Fatty liver, GalN, Hepatitis

\section{INTRODUCTION}

Liver diseases are a major problem throughout the world. Many environmental toxins cause liver injury to human, and despite new advances in hepatology, the treatment for liver diseases does not resolve the problems caused by these toxins. Furthermore despite the increasing need for agents to protect the liver from damage, modern medicine lacks a reliable liver protective drug (Park et al., 2008). Therefore, there has been considerable interest in the role of complementary and alternative medicines for the treatment of liver diseases (Galati et al., 2005). Recently, so-called health foods, including functional foods and dietary supplements, are being increasingly used world-wide on part of complementary and alternative medicine or self-medication

\footnotetext{
${ }^{*}$ Corresponding author

Tel: +82-31-290-7712, Fax: +82-31-292-8800

E-mail: sunmee@skku.edu
}

(Onishi and Yokoyama, 2004).

It is well known that the administration of carbon tetrachloride $\left(\mathrm{CCl}_{4}\right)$, ethionine and galactosamine (GaIN) lead to various forms of liver damage (Hatta et al., 1986). These models are frequently used in prospective studies on liver protecting agents because of experimental ease and their mechanisms of action are well-documented (Nakayama et al., 1989). GalN is a hepatotoxicant, an inducer in hepatic injury models, both in vivo and in vitro. In vivo, GalN causes hepatic damage resembling viral hepatitis and drug-induced hepatitis (MacDonald et al., 1987). The development of cholangiolitic hepatitis in human patients receiving certain drug therapies is a clinical concern (Haibior et al., 1994). In rodents, a similar profile of liver damage can be reproduced by the administration of naphthylisothiocyanate (ANIT), and understanding the mechanisms of ANIT-induced hepatotoxicity may provide clues to the pathogenesis of hepatitis in people (Zimmerman et al., 1978). This damage includes 
decreased bile flow, necrosis of bile duct epithelial cells, injury to periportal hepatic parenchymal cells and a pronounced infiltration of neutrophils into periportal regions (Roth and Dahm, 1997). The administration of ethionine to rats leads to a rapid fall in the concentration of adenosine triphosphate (ATP) in the liver (Bartels et al., 1963). The hepatic ATP deficiency is, in turn, followed by a striking inhibition of ribonucleic acid and protein synthesis. These metabolic alterations appear to be intimately related to the induction of fatty liver by ethionine (Farber et al., 1964).

Aloe vera commonly known as Ghee kanwar (Hindi) is a cactus-like plant that grows in hot, dry climates such as dessert. It's survival in such a harsh environment encourages people to believe that Aloe vera has wound-healing and antibiotic effects (Reynolds et al., 1999). An Aloe vera leaves is used in diseases of eyes and enlargements of spleen and liver (Chandan et al., 2007). And its liver protective function via anti-oxidative and anti-inflammatory effects are well known (Lim et al., 2003; Can et al., 2004). Silybum marianum (Milk thistle) is an herbal supplement used to treat liver and biliary disorders (PostWhite et al., 2007). It recently has been investigated for use as a cytoprotectant, an anticarcinogen, and a supportive treatment for liver damage from Amanita phalloides poisoning. Silymarin, an active ingredient of Silybum marianum, is a strong antioxidant that has been proved to promote liver cell regeneration, to reduce blood cholesterol and to help prevent cancer (Vaknin et al., 2007).

This study examined the hepatoprotective properties of ACTIValoe ${ }^{\circledR} \mathrm{N}-931$ complex, a mixture of Aloe vera and Silybum marianum

\section{MATERIALS AND METHODS}

\section{Chemicals and reagents}

ACTIValoe ${ }^{\circledR} \mathrm{N}-931$ complex was provided from Univera, Incorporation. ANIT, ethionine, GalN, glutathione, 2,6-di-tert-butyl-4-methylphenol and 2-thiobarbituric acid were purchased from the Sigma Chemical Co. USA. All other chemicals and reagents used in this study were of reagent grade available.

\section{Animals}

Male or female Sprague-Dawley rats weighing 240$260 \mathrm{~g}$ were obtained from Hyundai-Bio Animal Breeding Company of Korea. All the animals were treated humanely under the Sungkyunkwan University Animal Care Committee Guidelines. Rats were maintained in a room with controlled temperature and humidity $\left(25 \pm 1^{\circ} \mathrm{C}\right.$ and $55 \pm 5 \%$, respectively) with a $12 \mathrm{~h}$ light-dark cycle.

\section{Acute hepatotoxicity}

GalN was dissolved in phosphate buffered saline (PBS) and administered intraperitoneally $(700 \mathrm{mg} / \mathrm{kg}$ ). The male rats were randomly assigned to five groups: i) vehicle-treated control; ii) vehicle-treated GalN; iii) ACTIValoe ${ }^{\circledR} \mathrm{N}-931$ complex 85 (a mixture of Aloe vera $35 \mathrm{mg} /$ $\mathrm{kg}$ and Silybum marianum $50 \mathrm{mg} / \mathrm{kg}$ )-treated GalN; iv) ACTIValoe ${ }^{\circledR}$ N-931 complex 170 (a mixture of Aloe vera $70 \mathrm{mg} / \mathrm{kg}$ and Silybum marianum $100 \mathrm{mg} / \mathrm{kg}$ )-treated GalN; v) ACTIValoe ${ }^{\circledR}$ N-931 complex 340 (a mixture of Aloe vera $140 \mathrm{mg} / \mathrm{kg}$ and Silybum marianum $200 \mathrm{mg} / \mathrm{kg}$ )treated GalN. ACTIValoe ${ }^{\circledR} \mathrm{N}-931$ complex administered orally $48 \mathrm{~h}, 24 \mathrm{~h}$ and $2 \mathrm{~h}$ before and $6 \mathrm{~h}$ after GalN intraperitoneal injection. The dose and timing of ACTIValoe ${ }^{\circledR} \mathrm{N}$ 931 complex were selected based on previous reports (Lu et al., 2002; Chandan et al., 2007) and our preliminary studies. Blood samples were taken from the abdominal aorta and the liver was removed $24 \mathrm{~h}$ after GalNtreatment. ANIT was dissolved in olive oil and injected intraperitoneally $(40 \mathrm{mg} / \mathrm{kg}$ ). The male rats were randomly assigned to five groups: i) vehicle-treated control; ii) vehicle-treated ANIT; iii) ACTIValoe ${ }^{\circledR} \mathrm{N}-931$ complex 85-treated ANIT; iv) ACTIValoe ${ }^{\circledR} \mathrm{N}-931$ complex 170 treated ANIT; v) ACTIValoe ${ }^{\circledR} \mathrm{N}-931$ complex 340-treated ANIT. ACTIValoe ${ }^{\circledR} \mathrm{N}-931$ complex administered orally 48 $\mathrm{h}, 24 \mathrm{~h}$ and $2 \mathrm{~h}$ before and $6 \mathrm{~h}$ after ANIT intraperitoneal injection. The bile duct was cannulated with a polyethylene tube-10 and the bile flow was measured gravimetrically in prepared tubes. Blood samples were taken from the abdominal aorta and the liver was removed $48 \mathrm{~h}$ after ANIT-treatment. Ethionine was dissolved in PBS and injected intraperitoneally $(500 \mathrm{mg} / \mathrm{kg})$. The female rats were randomly assigned to five groups: i) vehicle-treated control; ii) vehicle-treated ethionine; iii) ACTIValoe ${ }^{\circledR} \mathrm{N}-931$ complex 85-treated ethionine; iv) ACTIValoe $^{\circledR} \mathrm{N}-931$ complex 170-treated ethionine; v) ACTIValoe $^{\circledR} \mathrm{N}-931$ complex 340-treated ethionine. ACTIValoe ${ }^{\circledR} \mathrm{N}-931$ complex administered orally $48 \mathrm{~h}, 24 \mathrm{~h}$ and $2 \mathrm{~h}$ before and 6 $\mathrm{h}$ after ethionine intraperitoneal injection. Blood samples were taken from the abdominal aorta and the liver was removed $24 \mathrm{~h}$ after ethionine treatment.

\section{Analytical procedures}

The levels of serum alanine aminotransferases (ALT), aspartate aminotransferase (AST) total cholesterol (TC) and triglyceride (TG) were determined by standard spectrophotometric procedures using the ChemiLab ALT, AST, 
TC and TG assay kit (IVDLab Co.,), respectively. The total glutathione level was measured spectrophotometrically at a wavelength of $412 \mathrm{~nm}$ using yeast glutathione reductase and 5, 5'-dithio-bis (2-nitrobenzoic acid), as described by Tietze (1969). The oxidized glutathione (GSSG) level was measured using the same method but in the presence of 2-vinylpyridine (Griffith, 1980). The level of reduced glutathione (GSH) was determined by the difference between the total glutathione and GSSG levels. The steady-state level of malondialdehyde (MDA), which is the end product of lipid peroxidation, in the liver was determined by measuring the level of thiobarbituric acid-reactive substances spectro photometically at 535 $\mathrm{nm}$ using the method described by Buege and Aust (1978). Bile flow was calculated from the volume of bile collected, time of collection, and liver wet weight and indicated as $\mathrm{ml} / \mathrm{min} / \mathrm{g}$ liver.

\section{Histopathological analysis}

The liver slices were made from a portion of left lobe, and fixed immediately in a $10 \%$ formalin buffered phosphate solution, embedded in paraffin and sectioned at $5 \mathrm{~mm}$ thickness. The serial sections were stained with hematoxylin and eosin (H\&E) to evaluate the portal inflammation, hepatocellular necrosis, inflammatory cell infiltration, macro- and micro-vesicular steatosis. The sections were examined in a blind manner under an Olympus CKX 41 microscope (Olympus optical Co. Ltd., Tokyo, Japan) (karaa et al., 2005).

\section{Statistical analysis}

All the results are presented as mean \pm S.E.M. Oneway analysis of the variance (ANOVA) followed by a Dunnett's test was used to determine the significance of the differences between the experimental groups. A $p$ value $<0.05$ was considered significant.

\section{RESULTS}

\section{Effect of ACTIValoe ${ }^{\circledR} \mathrm{N}-931$ complex on GalN- induced hepatitis}

The serum ALT activity in the control group was very low. The serum ALT activities increased markedly $24 \mathrm{~h}$ after the GalN injection. These increases were attenuated by the ACTIValoe ${ }^{\circledR} \mathrm{N}-931$ complex 170 . Similar to ALT activity, the serum AST activities increased significantly $24 \mathrm{~h}$ after GalN injection and these increases were attenuated by ACTIValoe ${ }^{\circledR} \mathrm{N}-931$ complex 85,170 and 340. The MDA level increased significantly in the GalNinjected rats. ACTIValoe ${ }^{\circledR} \mathrm{N}-931$ complex did not affect the level of MDA. GSH in the GalN-injected rats decreased to $77 \%$ of the control and this decrease was slightly attenuated by ACTIValoe ${ }^{\circledR} \mathrm{N}-931$ complex 170 and 340 (Table I). As shown in Fig. 1, the serum concen-

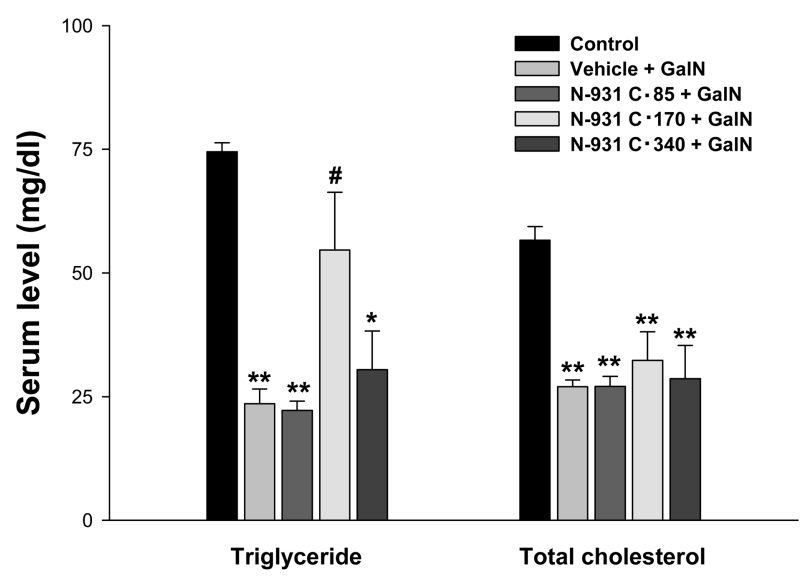

Fig. 1. Effect of ACTIValoe ${ }^{\circledR} \mathrm{N}-931$ complex on serum triglyceride and total cholesterol levels in GalN-induced hepatitis. The values are represented as the mean \pm SEM for 7-8 rats per group. ${ }^{*}{ }^{* *}$ Significantly different $(P<0.05, P<0.01)$ from control group. \#Significantly different $(P<0.05)$ from GalN group. GalN, D-galactosamine; N-931C, ACTIValoe ${ }^{\circledR} \mathrm{N}-931$ complex.

Table I. Effect of ACTIValoe ${ }^{\circledR} \mathrm{N}-931$ complex on the serum aminotransferase activity, hepatic lipid peroxidation and glutathione content in the GalN-induced rats

\begin{tabular}{ccccc}
\hline Treatment & $\begin{array}{c}\text { ALT } \\
(\mathrm{IU} / \mathrm{L})\end{array}$ & $\begin{array}{c}\text { AST } \\
(\mathrm{IU} / \mathrm{L})\end{array}$ & $\begin{array}{c}\text { MDA } \\
(\mathrm{nmol} / \mathrm{mg} \text { protein) }\end{array}$ & $\begin{array}{c}\text { GSH } \\
(\mathrm{mmol} / \mathrm{g} \mathrm{liver})\end{array}$ \\
\hline Control & $30.8 \pm 0.4$ & $110.0 \pm 3.2$ & $0.34 \pm 0.02$ & $8.5 \pm 0.4$ \\
Vehicle + GalN & $160.6 \pm 11.3^{* *}$ & $444.1 \pm 8.4^{* *}$ & $0.51 \pm 0.05^{* *}$ & $6.5 \pm 0.2^{* *}$ \\
N-931 C85 + GalN & $126.7 \pm 6.0^{* *}$ & $358.8 \pm 10.1^{* *}, \#$ & $0.46 \pm 0.03^{* *}$ & $6.6 \pm 0.4^{*}$ \\
N-931 C170 + GalN & $94.4 \pm 11.0^{*}, \# \#$ & $271.7 \pm 36.4^{*}, \# \#$ & $0.48 \pm 0.02^{* *}$ & $7.2 \pm 0.4$ \\
N-931 C340 + GalN & $109.5 \pm 4.7^{*}$ & $271.7 \pm 36.4^{* *}, \# \#$ & $0.52 \pm 0.04^{* *}$ & $7.6 \pm 0.4$ \\
\hline
\end{tabular}

The values are the mean \pm S.E.M. of 8 rats per group. ${ }^{*},{ }^{\star \star}$ Significantly different $(p<0.05, P<0.01)$ from the control group. ${ }^{\#, \# \text { Sig- }}$ nificantly different $(p<0.05,0.01)$ from the vehicle-treated GalN group. GalN, D-galactosamine N-931C, ACTIValoe ${ }^{\circledR} \mathrm{N}-931$ complex. 

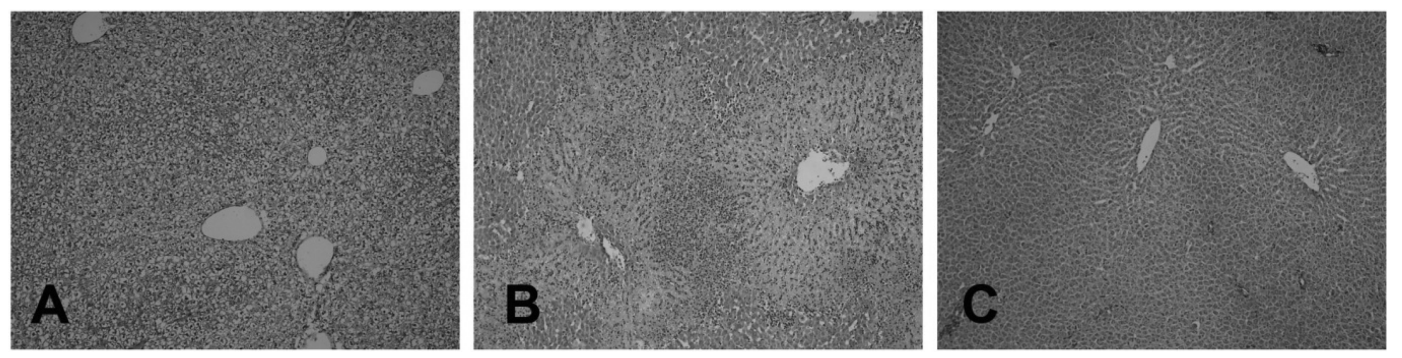

Fig. 2. Histological analysis of the livers after GalN administration. (A) Control, normal architecture of liver. (B) GalN, inflammation of lymphocytes and Kupffer cells and hyaline degeneration around the portal vein area. (C) ACTIValoe ${ }^{\circledR}$ N-931 complex+ GalN, minimal hepatocellular inflammatory cell infiltration and mild portal inflammation. All the photographs are at $\times 100$ magnification.

tration of TG in the control was $74.5 \pm 1.84 \mathrm{mg} / \mathrm{dl}$. The serum TG concentrations significantly decreased after the GalN-injected rats. These decreases were attenuated by the ATIValoe ${ }^{\circledR} \mathrm{N}-931$ complex 170. The serum TC levels in the GalN-injected group significantly decreased. ATIValoe ${ }^{\circledR} \mathrm{N}-931$ complex did not affect the level of serum TC. Histopathological analysis revealed that signs of liver injury were prominent at $24 \mathrm{~h}$ as a result of GalN injection, demonstrated by severe hepatocyte necrosis, inflammatory cells infiltration. ACTIValoe ${ }^{\circledR} \mathrm{N}-931 \mathrm{com}-$ plex significantly attenuated these pathological alteration in the liver of GalN-treated rats (Fig. 2).

\section{Effect of ACTIValoe ${ }^{\circledR} \mathrm{N}-931$ complex on ANIT- induced cholestasis}

The serum levels of ALT and AST in the control group were $30.8 \pm 0.40 \mathrm{IU} / \mathrm{l}$ and $100 \pm 10.0 \mathrm{IU} / \mathrm{l}$, respectively. 48 $\mathrm{h}$ after ANIT injection, the serum ALT and AST levels increased to approximately 39.0 and 20.4 times those in the control group, respectively. Treatment of ACTIValoe ${ }^{\circledR}$ $\mathrm{N}-931$ complex 170 significantly reduced these increases (Fig. 3). Bile flow in the control group was $1.26 \pm 0.02 \mu \mathrm{l} /$ $\mathrm{min} / \mathrm{g}$ liver. In the vehicle-treated ANIT group, the level of bile flow decreased to $0.17 \pm 0.04 \mu \mathrm{l} / \mathrm{min} / \mathrm{g}$ liver. The decrease in bile flow was markedly restored by ACTIValoe ${ }^{\circledR} \mathrm{N}-931$ complex 170. In contrast, the serum TB level increased significantly $48 \mathrm{~h}$ after ANIT injection, which was attenuated by ACTIValoe ${ }^{\circledR} \mathrm{N}-931$ complex 170 (Table II).

\section{Effect of ACTIValoe ${ }^{\circledR} \mathrm{N}-931$ complex on ethionine- induced fatty liver}

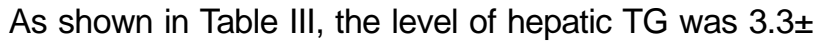
$0.3 \mathrm{mg} / \mathrm{g}$ liver in the control group. On the other hand, in the vehicle-treated ethionine group, the level of hepatic TG increased to 2 times that of the control group. This increase was significantly attenuated by treatment with ACTIValoe ${ }^{\circledR} \mathrm{N}-931$ complex 170 and 340 . The level of

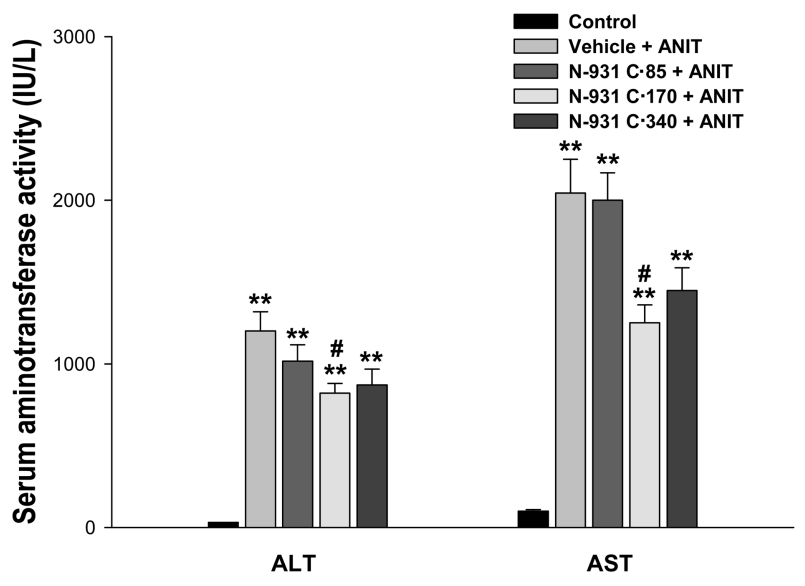

Fig. 3. Effect of $A C T I V a l o e^{\circledR} \mathrm{N}-931$ complex on serum ALT and AST activities in ANIT-induced cholestasis. The values are represented as the mean \pm SEM for 7-8 rats per group. ** Significantly different $(P<0.01)$ from control group. \#Significantly different $(P<0.05)$ from ANIT group. ANIT, $\alpha$-naphthylisothiocyanate; $\mathrm{N}-931 \mathrm{C}$, ACTIValoe ${ }^{\circledR} \mathrm{N}-931$ complex.

Table II. Effect of ACTIValoe ${ }^{\circledR} \mathrm{N}-931$ complex on the bile flow and serum total bilirubin in the ANIT -induced rats

\begin{tabular}{lcc}
\hline \multicolumn{1}{c}{ Treatment } & $\begin{array}{c}\text { Bile flow } \\
(\mu \mathrm{l} / \mathrm{min} / \mathrm{g} \text { liver })\end{array}$ & $\begin{array}{c}\text { Serum total bilirubin } \\
(\mathrm{mg} / \mathrm{dl})\end{array}$ \\
\hline Control & $1.26 \pm 0.02$ & $0.01 \pm 0.01$ \\
Vehicle + ANIT & $0.17 \pm 0.04^{* \star}$ & $0.70 \pm 0.05^{* *}$ \\
N-931 C85 + ANIT & $0.24 \pm 0.02^{* *}$ & $0.57 \pm 0.06$ \\
N-931 C170 + ANIT & $0.42 \pm 0.08^{* *}, \#$ & $0.37 \pm 0.05^{\#}$ \\
N-931 C340 + ANIT & $0.38 \pm 0.07^{* *}$ & $0.48 \pm 0.07$ \\
\hline
\end{tabular}

The values are the mean \pm S.E.M. of 8 rats per group. ${ }^{*}$ Significantly different $(p<0.01)$ from the control group. "Significantly different $(p<0.05)$ from the vehicle-treated ANIT group. ANIT, $\alpha$-naphthylisothiocyanate $\mathrm{N}-931 \mathrm{C}$, ACTIValoe ${ }^{\circledR} \mathrm{N}-931$ complex.

serum TC in control group was $55.9 \pm 2.06 \mathrm{mg} / \mathrm{dl}$. In the ethionine-treated group, the serum TC level significantly decreased to $12.8 \pm 3.09 \mathrm{mg} / \mathrm{dl}$. The ACTIValoe ${ }^{\circledR} \mathrm{N}-931$ 

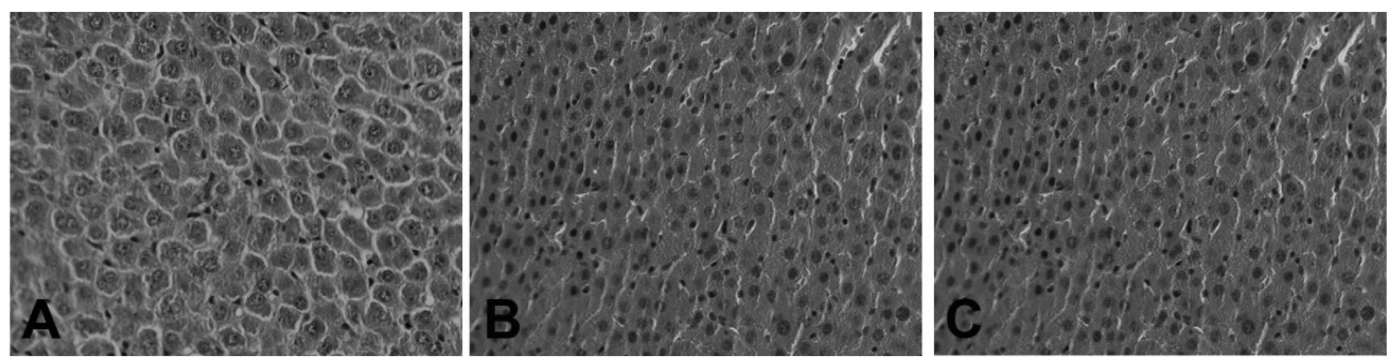

Fig. 4. Histological analysis of the liver after ethionine administration. (A) Control, normal hepatic parenchyma. (B) ethionine, extensive areas of fatty change and microvesicular steatosis were observed around cells. (C) ACTIValoe ${ }^{\circledR} \mathrm{N}-931$ complex + ethionine, minimal fatty change and mild microvesicular steatosis. All the photographs are at $x 400$ magnification.

Table III. Effect of ACTIValoe ${ }^{\circledR} \mathrm{N}-931$ complex on the liver triglyceride and serum total cholesterol in the ethionine induced rats

\begin{tabular}{lcc}
\hline Treatment & $\begin{array}{c}\text { Liver } \\
\text { triglyceride } \\
(\mathrm{mg} / \mathrm{g} \text { liver })\end{array}$ & $\begin{array}{c}\text { Serum total } \\
\text { cholesterol } \\
(\mathrm{mg} / \mathrm{dl})\end{array}$ \\
\hline Control & $3.38 \pm 0.33$ & $55.9 \pm 2.06$ \\
Vehicle + Ethionine & $6.87 \pm 0.31^{\star *}$ & $12.8 \pm 3.09^{\star *}$ \\
N-931 C85 + Ethionine & $5.84 \pm 0.95^{*}$ & $11.4 \pm 1.14^{* *}$ \\
N-931 C170 + Ethionine & $3.70 \pm 0.44^{\# \#}$ & $11.9 \pm 1.32^{* *}$ \\
N-931 C340 + Ethionine & $3.83 \pm 0.59^{\# \#}$ & $12.9 \pm 1.68^{* *}$ \\
\hline
\end{tabular}

The values are the mean \pm S.E.M. of 8 rats per group. ${ }^{*}$, Significantly different $(p<0.05, \quad P<0.01)$ from the control group. \#\#ignificantly different $(p<0.01)$ from the vehicletreated ethionine group. N-931C, ACTIValoe ${ }^{\circledR} \mathrm{N}-931$ complex.

complex did not affect the level of serum TC. Histopathological analysis revealed that signs of liver injury were prominent at $24 \mathrm{~h}$ as a result of ethionone injection, demonstrated by extensive areas of fatty change and microvesicular steatosis were observed around cells. These histopathological changes were ameliorated by ACTIValoe ${ }^{\circledR} \mathrm{N}-931$ complex (Fig. 4).

\section{DISCUSSION}

Drug/chemical-induced liver injury has been used as a model for screening hepatoprotective agents. Among these toxins, GalN is known as specific hepatotoxic agent. Its hepatotoxicity has much clinical importance because GalN-induced liver injury shows many metabolic and morphological aberrations in the liver of experimental animals, which is pathologically similar to those observed in human viral hepatitis (Nakama et al., 2001; Morikawa et al., 1996). The detail mechanism of GalNinduced hepatotoxicity has not been clearly established yet, but recent studies suggest that GalN induces the depletion of uracil nucleotides, resulting in inhibition of RNA and protein synthesis in liver and leading to damage of hepatocytes eventually (Kaplowitz et al., 2002; Jaeschke, 2002). Koff et al. (1971) observed marked accumulation of hepatic triglyceride, concluding that the cause of GalN-induced fatty liver was inhibition of synthesis of the protein moiety of lipoprotein.

In the vehicle-treated GalN group, the ALT and AST levels increased dramatically compared with the control group, indicating severe hepatocellular damage. In contrast, a treatment with ACTIValoe ${ }^{\circledR} \mathrm{N}-931$ complex markedly attenuated the release of ALT and AST. In our preliminary studies, Aloe vera or Silybum marianum alone suppressed the increase in the serum ALT and AST activities in GalN-induced rats. Combination of Aloe vera and Silybum marianum appeared to have a further synergistic effect in suppressed the increases in the serum aminotransferase activities (data not shown). The histo-pathological observations of liver sample strongly support the release of aminotransferase by the damaged hepatocytes as well as the protective effect of ACTIValoe ${ }^{\circledR}$ N-931 complex. GalN caused various histopathological changes to the liver, including cell necrosis, cell inflammation and ballooning degeneration. These alterations were significantly attenuated by ACTIValoe ${ }^{\circledR}$ N-931 complex. Furthermore, ACTIValoe ${ }^{\circledR} \mathrm{N}-931$ complex attenuated the decrease in TG concentration induced by GalN. These results indicate that ACTIValoe ${ }^{\circledR} \mathrm{N}-931$ complex may enhance lipoprotein synthesis and prevent the accumulation of lipid in liver.

The induction of cell death by GalN is associated with the generation of reactive oxygen species (ROS) in cultured hepatocytes (González et al., 2007). The presence of oxidative stress is caused by either an increase in ROS generation or a depletion of antioxidants. Different antioxidant strategies have shown to be useful to reduce 
oxidative stress and cell death in hepatocyte. GSH constitutes the first line of defense against free radicals and is a critical determinant of the tissue susceptibility to oxidative stress (Park et al., 2008). GalN significantly lowered the hepatic GSH level compared to control group. In contrast, the hepatic MDA level was higher than the control group. These results indicate ROS produced in the vehicle-treated GalN groups cause cell damage directly through GSH depletion and the subsequent lipid peroxidation. The treatment of ACTIValoe ${ }^{\circledR} \mathrm{N}-931$ complex slightly attenuated the decrease in hepatic GSH content but did not affect to the lipid peroxidation, which suggests that ACTIValoe ${ }^{\circledR} \mathrm{N}-931$ complex increases the hepatic pool of GSH and reduces oxidative stress.

ANIT is a toxicant that targets the bile duct and causes an intrahepatic cholestasis which is commonly used as model for human chronic cholangitic diseases (Plaa and Priestly, 1976). ANIT is thought to be bioactivated in the liver by cytochrome P450s. Normally bioactivated ANIT is detoxified in hepatocytes by conjugating with glutathione and catalysed by glutathione S-transferases. ANIT-glutathione complexes are transported into bile, then ANITconjugate damages bile-duct epithelial cells, causing cholangiolitis that leads to intrahepatic biliary obstruction and increases accumulation of toxic bile acids in the liver. Thus, ANIT induces hepatotoxicity which involves impair of xenobiotic metabolism and transport leading to cholestasis, inflammation and finally hepatocellular death (Roth et al., 1997). Accordingly total bilirubin concentration and bile flow rate are used as markers of ANITinduced hepatotoxicity in addition to ALT and AST activities. In our study, ALT and AST levels significantly increased in ANIT-induced rats. However, the increased ALT and AST levels markedly attenuated when ACTIValoe ${ }^{\circledR} \mathrm{N}-931$ complex were treated. Also, ANIT causes a significant increase in serum total bilirubin and decrease in bile flow. These changes were reversed by the treatment of ACTIValoe ${ }^{\circledR} \mathrm{N}-931$ complex. These results suggest that administration of $\mathrm{ACTIValoe}{ }^{\circledR} \mathrm{N}-931$ complex enhances bile flow and attenuates hyperbilirubinaemia, promoting recovery from hepatocellular injury.

Fatty liver results from the abnormal accumulation of triglyceride within the cytoplasm of hepatocyte and is a common histopathological finding in human liver biopsies (ljaz et al., 2003). The reported worldwide prevalence of fatty livers ranges from $16 \%$ to $26 \%$. Ethionine, causes steatosis in experimental animals of various species (Waterfield et al., 1998). Fat accumulation in the liver can be seen under the electron microscope as lipid droplets form 3-4 $\mathrm{h}$ after the administration of large doses of ethionine (100-1000 mg/kg) to rats (Farber et al., 1964). It has been suggested that the ethionine-induced accumulation of triglycerides in the liver is related to ATP deficiency, since ATP may participate in releasing hepatic triglycerides into the plasma (Farber et al., 1964). Ethionine induces cholesterol accumulation in liver via inhibition of lipoprotein synthesis and accordingly, serum total cholesterol and neutral lipid levels were decreased. In present study, the liver triglyceride contents of ethioninetreated group significantly increased compared with the control. This change was attenuated by ACTIValoe ${ }^{\circledR} \mathrm{N}$ 931 complex 170 and 340. Furthermore, the histopathological observation of liver strongly shows that ethionine induces extensive areas of fatty change and microvesicular steatosis around hepatocytes and theses change were significantly attenuated by ACTIValoe ${ }^{\circledR} \mathrm{N}-931$ complex.

Overall, it appears that ACTIValoe ${ }^{\circledR} \mathrm{N}-931$ complex protects hepatocytes from hepatotoxicity caused by GalN, ANIT and ethionine. This study provides evidence that ACTIValoe ${ }^{\circledR} \mathrm{N}-931$ complex may offer an alternative for the prevention of acute hepatic injury.

\section{REFERENCES}

Bartels, H. and Hohorst, H. J. (1963). On the effect of ethionine on the metabolite status of the rat liver. Biochim. Biophys. Acta 71, 214-216.

Buege, T. A. and Aust, S. D. (1978). Microsomal lipid peroxidation. Methods Enzymol. 52, 302-310.

Can, A., Akev, N., Ozsoy, N., Bolkent, S., Arda, B. P., Yanardag, R. and Okyar, A. (2004). Effect of Aloe vera leaf gel and pulp extracts on the liver in type-Il diabetic rat models. Biol. Pharm. Bull. 27, 694-698.

Chandan, B. K., Saxena, A. K., Shukla, S., Sharma, N., Gupta, D. K., Suri, K. A., Suri, J., Bhadauria, M. and Singh, B. (2007). Hepatoprotective potential of Aloe barbadensis Mill.against carbon tetrachloride induced hepatotoxicity. J. Ethnopharmacol. 111, 560-566.

Farber, E., Shull, K. H., Villa-trevino, S., Lombardi, B. and Thomas, M. (1964). Biochemical pathology of acute hepatic adenosinetriphosphate deficiency. Nature 203, 34-40.

Galati, E. M., Mondello, M. R., Lauriano, E. R., Taviano, M. F., Galluzzo,M. and Miceli, N. (2005). Opuntia ficus indica (L.) Mill. fruit juice protects liver from carbon tetrachloride-induced injury. Phytother. Res. 19, 796-800.

González, R., Collado, J. A., Nell, S., Briceño, J., Tamayo, M. J., Fraga, E., Bernardos, A., López-Cillero, P., Pascussi, J. M., Rufián, S., Vilarem, M. J., De la Mata, M., Brigelius-Flohe, R., Maurel, P. and Muntané, J. (2007). Cytoprotective properties of alpha-tocopherol are related to gene regulation in cultured D-galactosamine-treated human hepatocytes. Free Radic. Biol. Med. 43, 1439-1452.

Griffith, O. W. (1980). Determination of glutathione and glu- 
tathione disulfide using glutathione reductase and 2-vinylpyridine. Anal. Biochem. 106, 207-212.

Haibior, A., Walewska-Zielecka, B. and But ruk, E. (1994). Hepatocellular cholestasis liver injury due to amoxycillian-clavulanic acid combination. Clin. Inves. 72, 616-618.

Hatta, S., Suzuki, Y., Miyamoto, A., Take mura, H. and Ohshika, H. (1986). Effects of 8-(2-dimethylaminoethyl)-3-oxo-4-phenyl-1-thia-4,8-diazaspiro[4,5]decane dihydrochloride monohydrate (Y-8845) on carbontetrachloride-induced liver injury. Japan J. Pharmacol. 40, 561-567.

ljaz, S., Yang, W., Winslet, M. C. and Seifalian, A. M. (2003). Impairment of hepatic microcirculation in fatty liver. Microcirculation 10, 447-456.

Jaeschke, H. (2002). Redox considerations in hepatic injury and inflammation. Antioxid. Redox Signal 4, 699-700.

Kaplowitz, J. and Wilkerson, L. (2002). Reaching and teaching new medical students. Acad. Med. 77, 1173.

Karaa, A., Kamoun, W. S. and Clemens, M. G. (2005). Chronic ethanol sensitizes the liver to endotoxin via effects on endotherial nitric oxide synthesis regulation. Shock 24, 447-454.

Koff, R. S., Fitts, J. J., Sabesin, S. M. and Zimmerman, H. J. (1971). D-galactosamine hepatotoxicity. II. Mechanism of fatty liver production. Proc. Soc. Exp. Biol. Med. 138, 89-92.

Lim, B. O., Seong, N.S., Choue, R. W., Kim, J. D., Lee, H. Y., Kim, S. Y., Yu, B. P., Jeon, T. I. and Park, D. K. (2003). Efficacy of dietary Aloe vera supplementation on hepatic cholesterol and oxidative status in aged rats. J. Nutr. Sci. Vitaminol. 49, 292-296.

Lu, K. L., Tsai, C. C., Ho, L. K., Lin, C. C. and Chang, Y. S. (2002). Preventive effect of the Taiwan folk medicine Ixeris laevigata var. old hami on a naphthylisothiocyanate and carbon tetrachloride. Phytother. Res. 1, S45-50.

MacDonald, J. R., Beckstead, J. H. and Smuckler, E. A. (1987). An ultrastructural and histochemical study of the prominent inflammatory response in $\mathrm{D}(+)$-galactosamine hepatotoxicity. Br. J. Exp. Pathol. 68, 189-199.

Morikawa, J., Habuchi, Y., Nishio, M., Yamamoto, T., Tanaka, H. and Kashima, K. (1996). Delineation of premature P waves on four-dimensional electrocardiography, a new display of electrical forces by computer techniques. Angiology 47, 11011106.
Nakama, T., Nureki, O. and Yokoyama, S. (2001). Structural basis for the recognition of isoleucyl-adenylate and an antibiotic, mupirocin, by isoleucyl-tRNA synthetase. J .Biol. Chem. 276, 47387-47393.

Nakayama, S., Yamauchi, M. and Oguchi, S. (1989). A comparative study of Laennec by intravenous or subcutaneous injection on CCl4-induced acute or chronic liver injury in rats. Nippon Yakurigaku Zasshi 94, 137-144.

Ohnishi, N., and Yokoyama, T. (2004). Interaction between medicines and functional foods or dietary supplements. Keio $J$ Med. 53, 137-150.

Park, S. W., Lee C. H., Kim, Y. S., Kang, S. S. and Lee, S. M. (2008) Protective effect of bicalin against carbon tetrachloride-induced acute hepatic injury in mice. J. Pharmacol Sci. 106, 136-143.

Plaa, G. L. and Priestly, B. G. (1976). Intrahepatic cholestasis induced by drugs chemicals. Pharmacol. Rev. 28, 207-273.

Post-White, J., Ladas, E. J. and Kelly, K. M. (2007). Advances in the use of milk thistle (Silybum marianum). Integr. Cancer. Ther. 6, 158-165.

Roch, R. A. and Dahm, L. J. (1997). Neutrophil-and glutathiomediated hepatotoxicity of a-naphthyliosothiocyanate. Drug Metab. Rev. 29, 153-165.

Roth, R. A., Harkema, J. R., Pestka, J. P. and Ganey, P. E. (1997). Is exposure to bacterial endotoxin a determinant of susceptibility to intoxication from xenobiotic agents? Toxicol. Appl. Pharmacol. 147, 300-311.

Tietze, F. (1969). Enzymic method for quantitative determination of nanogram amounts of total and oxidized glutathione: applications to mammalian blood and other tissues. Anal Biochem. 27, 502-522.

Vaknin, Y., Hadas, R., Schafferman, D., Murkhovsky, L. and Bashan, N. (2007). The potential of milk thistle (Silybum marianum L.), an Israeli native, as a source of edible sprouts rich in antioxidants. Int. J .Food Sci. Nutr. 20, 1-8.

Waterfield, C. J., Westmoreland, C., Asker, D. S., Murdock, J. C., George, E. and Timbrell, J. A. (1998). Ethionine toxicity in vitro: the correlation of data from rat hepatocyte suspensions and monolayers with in vivo observations. Arch. Toxicol. 72, 588-596.

Zimmerman, H. J. (1978). Drug-induced liver disease. Drugs 19, 25-45. 